Lothar A. Schwarte

Ingo Schwartges

Kai Thomas

Patrick Schober

Olaf Picker

\section{The effects of levosimendan and glibenclamide on circulatory and metabolic variables in a canine model of acute hypoxia}

Received: 10 August 2010

Accepted: 23 January 2011

Published online: 5 March 2011

(C) The Author(s) 2011. This article is published with open access at Springerlink.com

This article is discussed in the editorial available at doi:10.1007/s00134-011-2204-6.
L. A. Schwarte $(\bowtie) \cdot$ P. Schober Department of Anaesthesiology, VU University Medical Center, Amsterdam, The Netherlands e-mail: L.Schwarte@vumc.nl

I. Schwartges · K. Thomas - O. Picker Department of Anaesthesiology, University Hospital Duesseldorf, Duesseldorf, Germany
Abstract Purpose: To study the effects of pretreatment with levosimendan (LEVO, a Ca ${ }^{2+}$-sensitizer and $\mathrm{K}_{\mathrm{ATP}}^{+}$channel opener) and/or the $\mathrm{K}_{\mathrm{ATP}}^{+}$channel antagonist glibenclamide (GLIB) on systemic hemodynamics, metabolism, and regional gastromucosal oxygenation during hypoxic hypoxemia. Methods: Chronically instrumented, healthy dogs (24-32 kg, $n=6$ per group, randomized cross-over design) were repeatedly sedated, mechanically ventilated $\left(\mathrm{FiO}_{2} \sim 0.3\right)$ and subjected to the following interventions: no pretreatment, LEVO pretreatment, GLIB pretreatment, or combined LEVO + GLIB pretreatment, each followed by hypoxic hypoxemia $\left(\mathrm{FiO}_{2} \sim 0.1\right)$. We measured cardiac output (CO, ultrasonic flow probes), oxygen consumption $\left(\mathrm{VO}_{2}\right.$, indirect calorimetry), and gastromucosal microvascular hemoglobin oxygenation $\left(\mu \mathrm{HbO}_{2}\right.$, spectrophotometry). Statistics: data are presented as mean \pm SEM and compared by one-way ANOVA (direct drug effects within group) and two-way ANOVA (between all hypoxic conditions) both with Bonferroni corrections; $p<0.05$. Results: In LEVO-pretreated hypoxemia, CO was significantly higher compared to unpretreated hypoxemia. The increased $\mathrm{CO}$ was neither associated with an increased $\mathrm{VO}_{2}$ nor with markers of aggravated anaerobiosis ( $\mathrm{pH}, \mathrm{BE}$, lactate). In addition, LEVO pretreatment did not further compromise gastromucosal $\mu \mathrm{HbO}_{2}$ in hypoxemia. After combined LEVO + GLIB pretreatment, systemic effects of GLIB were apparent, however, $\mathrm{CO}$ was significantly higher than during unpretreated and GLIBpretreated hypoxemia, but equal to LEVO-pretreated hypoxemia, indicating that GLIB did not prevent the increased CO in LEVO-pretreated hypoxia. Conclusions: LEVO pretreatment resulted in improved systemic circulation (CO) during hypoxemia without fueling systemic $\mathrm{VO}_{2}$, without aggravating systemic anaerobiosis markers, and without further compromising microvascular gastromucosal oxygenation. Thus, LEVO pretreatment may be an option to support the systemic circulation during hypoxia.

Keywords Levosimendan . Hypoxia - Glibenclamide . Microcirculation - Oxygen . Metabolism 


\section{Introduction}

Hypoxemia complicates critical care settings, ranging from progressed lung disease to certain medical interventions [1-3]. Clearly, reversing hypoxemia is pivotal [4], but adapting pharmacological interventions to support the subject during impending or actual hypoxemia also appears beneficial. Systemic hypoxemia triggers multiple patho-mechanisms [5] also affecting the cardiovascular system: among others, at the cardiac level hypoxia depresses cardiac function by myofilament $\mathrm{Ca}^{2+}$-desensitization $[6,7]$, and at the vascular level hypoxia triggers activation of $\mathrm{K}_{\mathrm{ATP}}^{+}$channels [8], facilitating blood flow to tissues otherwise at risk for hypoperfusion by intense vasoconstriction.

In this context, the inodilator levosimendan (LEVO) appears to be an attractive option to support the cardiovascular system at risk in (impending) hypoxemia since it acts both as cardiac myofilament $\mathrm{Ca}^{2+}$-sensitizer and $\mathrm{K}_{\mathrm{ATP}}^{+}$channel opener, thus reversing hypoxia-induced cardiodepression and supporting regional vasodilation. This appears to be particularly of interest in hypoxic settings, since LEVO putatively increases cardiac output (CO) partly independent of an additional increase in oxygen consumption $\left(\mathrm{VO}_{2}\right)$ [9].

Hypoxia, like other cardiovascular stressors, triggers impairment of splanchnic oxygenation, likely through a combination of abnormal mesenteric perfusion [10-12] and hypoxemia. However, particularly the gastrointestinal mucosa is susceptible to hypoxia, and mucosal hypoxia appears to trigger the development of critical illness [13]. Thus, interventions intended to improve systemic (hemodynamic) variables during hypoxia should not further compromise regional mucosal circulation or oxygenation [14]. Therefore, in addition to systemic variables, we measured the effects on regional gastromucosal oxygenation.

Clinically, LEVO is primarily indicated for the treatment of acute and chronic ischemic cardiac failure, with promising clinical data available $[15,16]$. Moreover, LEVO is also increasingly advocated to treat nonischemic cardiac failure, including septic or toxic cardiodepression [17-23]. The beneficial effects of LEVO, in addition to positive inotropic effects, may be caused by vasodilation [24]. Mechanistically, vasodilation by LEVO is mediated by activation of $\mathrm{K}_{\text {ATP }}^{+}$channels, which also appear involved in the vasodilation triggered by hypoxia $[8,25]$.

These $\mathrm{K}_{\mathrm{ATP}}^{+}$channels, activated by LEVO or hypoxia, are pharmacologically blocked by glibenclamide (GLIB) [26-30]. In this context, GLIB pretreatment has previously been published as a research tool to study the contribution of GLIB-sensitive $\mathrm{K}_{\mathrm{ATP}}^{+}$channels to the effects of LEVO and other cardiovascular challenges [2630]. Thus, to elucidate the contribution of $\mathrm{K}_{\mathrm{ATP}}^{+}$channels in the present study, we tested if $\mathrm{K}_{\mathrm{ATP}}^{+}$channel blockade by GLIB pretreatment would alter the (circulatory) condition during hypoxia, both with and without a LEVO pretreatment.

GLIB, based on the same mechanism, i.e., antagonizing $\mathrm{K}_{\mathrm{ATP}}^{+}$channel-dependent vasodilation, is of growing interest in intensive care medicine [31]. In this context, GLIB is studied as nonadrenergic vasopressor in various shock-related vasodilatory states, caused by excessive $\mathrm{K}_{\mathrm{ATP}}^{+}$channel activation. Examples for this therapeutic concept are septic or hemorrhagic vasodilation $[32,33]$. In this regard, GLIB increases systemic vascular resistance and thus arterial blood pressure [32].

In the present study, the combination of LEVO (to increase cardiac contractility) and GLIB (to increase systemic vascular resistance) could achieve the putatively beneficial combination of antagonizing both possible cardiodepressant and vasodilatory effects of systemic hypoxia.

\section{Materials and methods}

The data derive from repetitive experiments on healthy dogs (foxhounds, $n=6,24-32 \mathrm{~kg}$ ) treated in accordance with the National Institutes of Health guidelines for animal care and with approval of the District Governmental Animal Investigation Committee.

For the continuous measurement of cardiac output (CO), ultrasonic flow transducers (S-series, Transonic, Ithaca, NY, USA) were chronically implanted around the pulmonary artery [34]. Before the experiments, food was withheld for $12 \mathrm{~h}$. The experiments were performed under sedation with sevoflurane (end-tidal concentration 3.0 vol\%, corresponding to $\sim 1.25 \mathrm{MAC}$ in $\operatorname{dogs}$ [35]) and neuromuscular block (rocuronium $0.6 \mathrm{mg} \mathrm{kg}^{-1}$, followed by $\left.1.0 \mathrm{mg} \mathrm{kg}^{-1} \mathrm{~h}^{-1}\right)$. Mechanical ventilation $\left(\mathrm{FiO}_{2} 0.3\right.$; tidal volume $12.5 \mathrm{~mL} \mathrm{~kg}^{-1}$ in dogs [36], respiratory rate $\sim 20 \mathrm{~min}^{-1}$ ) was adjusted to maintain normocapnia as verified by continuous capnography (end-tidal $\mathrm{CO}_{2}$ 35 torr) and arterial blood gas analysis. The dogs were covered with warming blankets to maintain body temperature $\left(\sim 37.5^{\circ} \mathrm{C}\right.$, rectal thermoprobe) .

\section{Measurements}

\section{Systemic oxygen consumption}

Systemic oxygen consumption $\left(\mathrm{VO}_{2}\right)$ was measured continuously by indirect calorimetry (Deltatrac-II metabolic monitor, Datex, Helsinki, Finland) and thus was methodologically independent from the determination of $\mathrm{CO}$ and $\mathrm{DO}_{2}[9]$. 
Systemic hemodynamics and oxygenation

We continuously measured heart rate (HR, electrocardiogram), mean arterial (aortic) pressure (MAP; P23ID, Elk Grove, CA, USA), central venous pressure (P23ID; right atrial catheter tip position confirmed by fluoroscopy), and ultrasound-derived CO (flowmeter T106, Transonic). At the end of each intervention, we performed transpulmonary thermodilution (PiCCO monitor with thermistor-tipped carotid catheter PV-2014L, Pulsion, Munich, Germany; measurements performed according to the manufacturer; with $\sim 0.4 \mathrm{~mL} \mathrm{~kg}^{-1}$ iced saline) to determine the following: global end diastolic volume (GEDV), derived intrathoracic blood volume (ITBV), and extravascular lung water (EVLW). The PiCCO system also provided the pulse-contour-derived stroke volume variation (SVV) and the estimate of cardiac contractility $+\mathrm{d} P / \mathrm{d} t_{\max }$. This system is validated to measure EVLW in dogs [37] and has also been applied in other canine studies [38].

Intermittently we measured arterial blood gas tensions $\left(\mathrm{PaO}_{2}, \mathrm{PaCO}_{2}\right)$ and acid/base-related variables $[\mathrm{pH}$, base excess (BE); ABL-700, Radiometer, Copenhagen, Denmark; no buffer solutions were used]. Additionally, we determined arterial serum metabolites (glucose, lactate) and electrolytes $\left(\left[\mathrm{K}^{+}\right],\left[\mathrm{Ca}^{2+}\right],\left[\mathrm{Na}^{+}\right],\left[\mathrm{Cl}^{-}\right]\right)$. According to standard formulas, we calculated systemic vascular resistance (SVR), arterial oxygen content $\left(\mathrm{CaO}_{2}\right)$, and systemic oxygen transport $\left(\mathrm{DO}_{2}\right)$.

\section{Gastromucosal oxygenation}

Gastromucosal oxygenation was continuously assessed by reflectance spectrophotometry [9, 39]. Briefly, light $(502-628 \mathrm{~nm})$ is transmitted to the tissue via a micro light guide, and the reflected light is analyzed for the percentage of oxygenated microvascular hemoglobin $\left(\mu \mathrm{HbO}_{2}\right)$. The flexible probe (diameter $2.0 \mathrm{~mm}$ ) was introduced into the stomach via an orogastric silicone tube (14 Charrière). During the experiments, correct probe position was confirmed by online evaluation of the signal quality (software version 2.0).

\section{Experimental program}

After induction (propofol $4 \mathrm{mg} \mathrm{kg}^{-1}$ i.v.) and endotracheal intubation, all catheters were inserted and $30 \mathrm{~min}$ was allowed to establish steady-state conditions. Blood was sampled for baseline analysis, and thereafter a randomization was performed to allocate the dogs to the experimental groups.

\section{Hypoxia episodes}

The hypoxic episodes were induced by switching $\mathrm{FiO}_{2}$ from 0.30 to 0.11 [40], as continuously measured (Capnomac ultima, Datex Instrumentarium, Helsinki, Finland). Each hypoxic episode was maintained for 15 min to allow steady states of the measured variables to be achieved.

\section{Drugs}

The agents LEVO and GLIB were infused as follows by a pressure-limited infusion pump via the central venous catheter.

\section{$L E V O$}

After baseline measurements, LEVO (Simdax, Abbott, Wiesbaden, Germany) was administered with an initial loading dose of $20.0 \mu \mathrm{g} \mathrm{kg}^{-1}$ over $15 \mathrm{~min}$, followed by continuous infusion of $0.25 \mu \mathrm{g} \mathrm{kg}^{-1} \mathrm{~min}^{-1}$ for the remaining experimental period, a dosing regimen adapted from a similar canine model [9].

\section{$G L I B$}

GLIB (G0639, Sigma, Frankfurt, Germany), as $\mathrm{K}_{\mathrm{ATP}}^{+}$channel antagonist, was infused at a dose of $0.2 \mathrm{mg} \mathrm{kg}{ }^{-1}$ over $10 \mathrm{~min}$, and $30 \mathrm{~min}$ were allowed for stabilization. This dose was derived from previous canine studies addressing the contribution of $\mathrm{K}_{\mathrm{ATP}}^{+}$channels to the effects of LEVO and other cardiovascular modulators [26-30].

\section{Experimental protocols}

\section{Group I}

This protocol served to study the effects of hypoxia per se and to study the associated effects of GLIB pretreatment. After steady-state baseline measurements, a first hypoxic challenge was performed. After 60 min recovery from this hypoxia (measurements after 30 and $60 \mathrm{~min}$ recovery), GLIB was infused. Following this GLIB pretreatment, a second hypoxic episode was induced.

\section{Group II}

This protocol served to study the effects of LEVO pretreatment on hypoxia and further to study the role of GLIB pretreatment in this regard. After a baseline period, 
LEVO pretreatment was administered, and thereafter a first hypoxic episode was induced. After 60 min recovery from this hypoxia (measurements after 30 and $60 \mathrm{~min}$ recovery), with LEVO continuously infused, GLIB pretreatment was administered. Thereafter, with the combined LEVO + GLIB pretreatment, a second hypoxic challenge was induced.

\section{Statistical analysis}

Statistical analysis was performed using Prism software (version 5.0, GraphPad, La Jolla, CA, USA). Data are presented as absolute values of mean \pm SEM for $n=6$ animals per group in the manuscript and tables. Direct drug effects (before onset of hypoxemia) were described by one-way ANOVA for repeated measurements, corrected for multiple comparisons (Bonferroni). Differences during hypoxemia were tested both between groups (i.e., I and II) and between the hypoxia conditions (i.e., without and with GLIB pretreatment) using a two-way ANOVA, corrected for multiple comparisons (Bonferroni). Significance was assumed at $p<0.05$.

\section{Results}

Hypoxia model

Hypoxia was induced by reducing $\mathrm{FiO}_{2}$ from 0.3 to 0.11 , with maintenance of end-tidal $\mathrm{CO}_{2}$ (35 torr) and end-tidal sevoflurane $(3.0 \mathrm{vol} \%)$ concentrations. This was achieved for all four hypoxic conditions without significant interor intragroup differences (Table 1).

Hypoxia in unpretreated animals

In our hypoxia model, reduction of $\mathrm{FiO}_{2}$ from 0.3 to 0.11 in unpretreated animals decreased $\mathrm{PaO}_{2}$ from $133 \pm 9$ to $39 \pm 1$ Torr and thereby $\mathrm{SaO}_{2}$ from $98 \pm 0$ to $68 \pm 1 \%$. Together with an unchanged $\mathrm{Hb}$ (stable at $\sim 12.5 \mathrm{~g} \mathrm{dL}^{-1}$, data not shown) this decreased $\mathrm{CaO}_{2}$ from $17.3 \pm 0.8$ to $11.7 \pm 0.6 \mathrm{~mL} \mathrm{dL}^{-1}$ (Table 1). At the regional level, gastromucosal $\mu \mathrm{HbO}_{2}$ decreased from $56 \pm 3$ to $32 \pm 4 \%$ (Fig. 1). $\mathrm{DO}_{2}$ decreased from $14 \pm 1$ to $9 \pm 1 \mathrm{~mL} \mathrm{~kg}^{-1} \mathrm{~min}^{-1}$, since $\mathrm{CaO}_{2}$ decreased without compensatory increase in $\mathrm{CO}$. However, systemic $\mathrm{VO}_{2}$ was preserved at $\sim 3.5 \mathrm{~mL} \mathrm{~kg}^{-1} \min ^{-1}$ (Table 2). Mechanical ventilation adjusted to maintain etCO $\mathrm{O}_{2}$ at 35 Torr maintained $\mathrm{PaCO}_{2}$ at 35-38 Torr. Acid/baserelated variables remained stable, i.e., $\mathrm{pH}$ at 7.35-7.37 and $\mathrm{HCO}_{3}^{-}$at $\sim 20 \mathrm{mmol} \mathrm{L}^{-1}$. Glucose and lactate (Table 1) and all measured electrolytes remained close to baseline (data not shown).
Hypoxia in GLIB-pretreated animals

GLIB pretreatment, used to block GLIB-sensitive $\mathrm{K}_{\text {ATP }}^{+}$channels, significantly increased SVR and significantly affected some blood-derived variables, e.g., it decreased arterial glucose concentration (Tables 1, 2).

Hypoxia after GLIB pretreatment resulted in a similar decreased $\mathrm{CaO}_{2}\left(11.1 \pm 0.5 \mathrm{~mL} \mathrm{dL}^{-1}\right)$, compared to unpretreated animals $\left(11.7 \pm 0.6 \mathrm{~mL} \mathrm{dL}^{-1}\right)$. Also, no statistical differences were observed in ventilation- and acid/base-derived parameters $\left(\mathrm{PaCO}_{2}, \mathrm{pH}\right.$, and $\left.\mathrm{BE}\right)$ and the $\mathrm{O}_{2}$-related variables $\mu \mathrm{HbO}_{2}, \mathrm{DO}_{2}$, and $\mathrm{VO}_{2}$ between these two hypoxic conditions. However, in GLIB-pretreated hypoxia, arterial lactate was significantly lower $\left(\sim 1.2 \mathrm{mmol} \mathrm{L}{ }^{-1}\right)$ compared to unpretreated hypoxia $\left(\sim 2.6 \mathrm{mmol} \mathrm{L}^{-1}\right)$. Systemic hemodynamics (i.e., MAP and $\mathrm{CO}$ ) did not differ between these two hypoxic episodes. Arterial electrolytes did not differ, and arterial glucose was significantly lower in GLIB-pretreated hypoxia $\left(\sim 80 \mathrm{mg} \mathrm{dL}^{-1}\right)$ compared to unpretreated hypoxia $\left(\sim 110 \mathrm{mg} \mathrm{dL}^{-1}\right)$ (Table 1$)$.

Hypoxia in LEVO-pretreated animals

LEVO pretreatment at the macrocirculatory level significantly increased $\mathrm{SV}, \mathrm{CO},+\mathrm{d} P / \mathrm{d} t_{\max }$, and $\mathrm{DO}_{2}$ and decreased SVR, without significant changes in HR. At the microcirculatory level, LEVO pretreatment significantly increased $\mu \mathrm{HbO}_{2}$ at a stable systemic $\mathrm{SaO}_{2}$.

Hypoxia after LEVO pretreatment resulted in a similar decrease in $\mathrm{CaO}_{2}$ to $10.3 \pm 0.5 \mathrm{~mL} \mathrm{dL}^{-1}$, compared to unpretreated animals. In LEVO-pretreated hypoxia, CO was significantly higher compared to unpretreated hypoxia, i.e., $\sim 100$ versus $\sim 80 \mathrm{~mL} \mathrm{~kg}^{-1} \mathrm{~min}^{-1}$ (Figs. 2, 3). This was not paralleled by systemic $\mathrm{VO}_{2}$, which was comparable to unpretreated animals at $\sim 3.5 \mathrm{~mL} \mathrm{~kg}^{-1} \mathrm{~min}^{-1}$. Also gastromucosal $\mu \mathrm{HbO}_{2}$ equally decreased in both unpretreated and LEVO-pretreated animals to $\sim 30 \%$ (Fig. 1). Systemic vascular resistance was significantly lower in LEVO-pretreated hypoxia, compared to unpretreated hypoxia.

\section{Hypoxia in LEVO- plus GLIB-pretreated animals}

Administration of GLIB during LEVO infusion induced significant effects, e.g., GLIB significantly decreased serum glucose from $103 \pm 4$ to $87 \pm 3 \mathrm{mg} \mathrm{dL}^{-1}$ (Table 1).

Hypoxic ventilation under combined pretreatment with LEVO and GLIB resulted in a $\mathrm{PaO}_{2}$ of 32 Torr. During hypoxia with LEVO + GLIB pretreatment, $\mathrm{CaO}_{2}$ tended to be lower compared to unpretreated hypoxia $\left(9.4 \pm 0.9\right.$ vs. $\left.11.7 \pm 0.6 \mathrm{~mL} \mathrm{dL}^{-1}\right)$, however, without statistical significance. $\mathrm{CO}$ was significantly higher than during hypoxia in solely GLIB-pretreated animals and did 


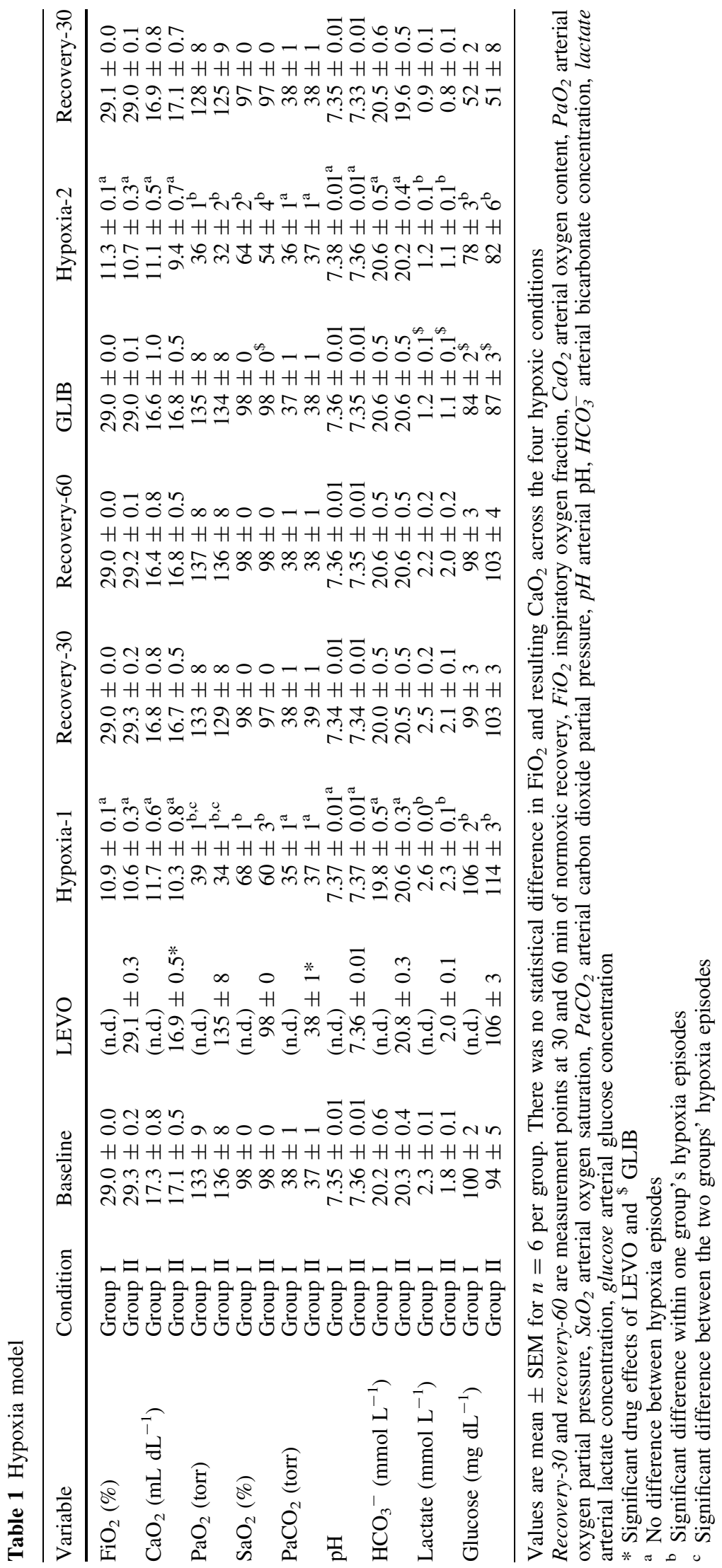




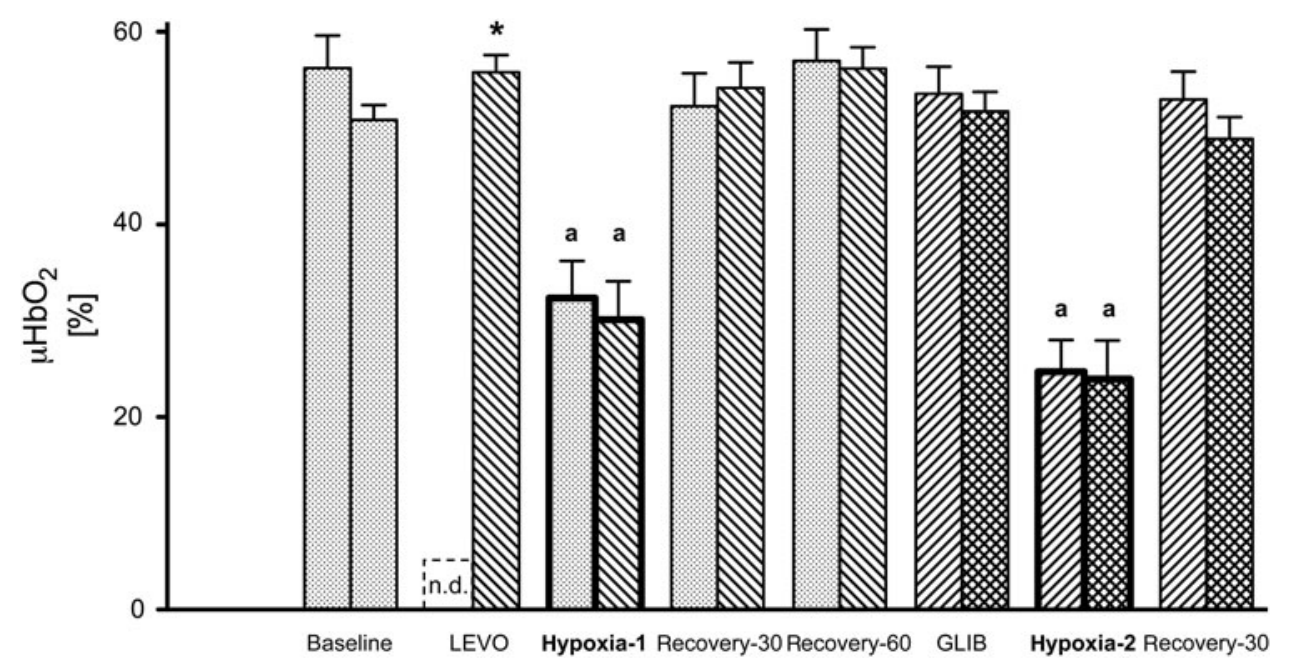

Fig. 1 Gastric mucosal microcirculatory hemoglobin oxygenation $\left(\mu \mathrm{HbO}_{2}\right)$. Gastromucosal $\mu \mathrm{HbO}_{2}$ during normoxia $\left(\mathrm{FiO}_{2} \sim 0.3\right.$, thin outlined bars $)$ and the two hypoxia episodes $\left(\mathrm{FiO}_{2} \sim 0.1\right.$, bold outlined bars) of the two experimental groups I (left bar per condition) and II (right bar per condition). Levosimendan was not given in group I, thus condition LEVO in group I is not determined (n.d.). Filling patterns: gray no pretreatment, downward stripes levosimendan (LEVO) pretreatment, upward stripes glibenclamide
(GLIB) pretreatment, hatches levosimendan + glibenclamide pretreatment. Recovery-30 and recovery-60 are measurement points at 30 and 60 min of normoxic recovery. Mean \pm SEM for $n=6$ per group. ${ }^{\mathrm{a}}$ No difference between hypoxia episodes, ${ }^{\mathrm{b}}$ significant difference within one group's hypoxia episodes, "significant difference between the two groups' hypoxia episodes, * significant drug effects of LEVO and ${ }^{\$}$ GLIB

Table 2 Systemic hemodynamic variables and systemic oxygen metabolism

\begin{tabular}{|c|c|c|c|c|c|c|c|c|c|}
\hline Variable & Condition & Baseline & LEVO & Hypoxia-1 & Recovery-30 & Recovery-60 & GLIB & Hypoxia-2 & Recovery-30 \\
\hline \multirow[t]{2}{*}{ SV $(\mathrm{mL})$} & Group I & $18 \pm 1$ & (n.d.) & $17 \pm 1^{\mathrm{b}}$ & $18 \pm 1$ & $18 \pm 1$ & $17 \pm 1$ & $15 \pm 1^{\mathrm{b}}$ & $17 \pm 1$ \\
\hline & Group II & $20 \pm 1$ & $22 \pm 1 *$ & $21 \pm 1^{\mathrm{b}}$ & $22 \pm 1$ & $22 \pm 1$ & $21 \pm 1$ & $21 \pm 1^{\mathrm{b}}$ & $20 \pm 1$ \\
\hline \multirow[t]{2}{*}{ HR (bpm) } & Group I & $116 \pm 3$ & (n.d.) & $121 \pm 2^{\mathrm{a}}$ & $114 \pm 3$ & $113 \pm 3$ & $112 \pm 2$ & $117 \pm 2^{\mathrm{a}}$ & $112 \pm 2$ \\
\hline & Group II & $111 \pm 6$ & $117 \pm 6$ & $126 \pm 4^{\mathrm{a}}$ & $116 \pm 5$ & $117 \pm 5$ & $116 \pm 4$ & $124 \pm 4^{\mathrm{a}}$ & $119 \pm 4$ \\
\hline \multirow[t]{2}{*}{ MAP $(\mathrm{mmHg})$} & Group I & $62 \pm 3$ & (n.d.) & $66 \pm 4^{\mathrm{a}}$ & $63 \pm 2$ & $62 \pm 2$ & $65 \pm 2$ & $62 \pm 4^{\mathrm{a}}$ & $63 \pm 1$ \\
\hline & Group II & $61 \pm 1$ & $62 \pm 1$ & $67 \pm 4^{\mathrm{a}}$ & $64 \pm 2$ & $62 \pm 1$ & $61 \pm 2$ & $65 \pm 6^{\mathrm{a}}$ & $61 \pm 2$ \\
\hline \multirow[t]{2}{*}{ SVR (dyn s $\mathrm{cm}^{-5}$ ) } & Group I & $2,468 \pm 235$ & (n.d.) & $2,647 \pm 165^{\mathrm{c}}$ & $2,502 \pm 131$ & $2,403 \pm 127$ & $2,792 \pm 224^{\$}$ & $2,765 \pm 118^{c}$ & $2,720 \pm 113$ \\
\hline & Group II & $2,295 \pm 127$ & $1,943 \pm 87 *$ & $2,039 \pm 162^{\mathrm{c}}$ & $2,024 \pm 98$ & $1,969 \pm 84$ & $2,006 \pm 78$ & $2,014 \pm 178^{\mathrm{c}}$ & $2,071 \pm 93$ \\
\hline \multirow{2}{*}{$\mathrm{VO}_{2}\left(\mathrm{~mL} \mathrm{~kg}^{-1} \min ^{-1}\right)$} & Group I & $3.5 \pm 0.1$ & (n.d.) & $3.4 \pm 0.1^{\mathrm{a}}$ & $3.7 \pm 0.1$ & $3.7 \pm 0.1$ & $4.1 \pm 0.1^{\$}$ & $3.6 \pm 0.1^{\mathrm{a}}$ & $4.2 \pm 0.1$ \\
\hline & Group II & $3.3 \pm 0.2$ & $3.7 \pm 0.2$ & $3.3 \pm 0.3^{\mathrm{a}}$ & $3.5 \pm 0.1$ & $3.6 \pm 0.1$ & $3.8 \pm 0.1$ & $3.5 \pm 0.2^{\mathrm{a}}$ & $3.5 \pm 0.2$ \\
\hline
\end{tabular}

Values are mean \pm SEM for $n=6$ per group

Recovery-30 and recovery- 60 are measurement points at 30 and $60 \mathrm{~min}$ of normoxic recovery, $H R$ heart rate, MAP mean arterial pressure, SVR systemic vascular resistance, $\mathrm{VO}_{2}$ systemic oxygen consumption

* Significant drug effects of LEVO and ${ }^{\$}$ GLIB
${ }^{\text {a }}$ No difference between hypoxia episodes

Significant difference within one group's hypoxia episodes

' Significant difference between the two groups' hypoxia episodes not differ from solely LEVO-pretreated animals (Fig. 2). SVR was significantly lower in LEVO + GLIB-pretreated hypoxia compared to GLIB-pretreated hypoxia. Systemic $\mathrm{VO}_{2}$ was comparable to all other hypoxic conditions at $\sim 3.5 \mathrm{~mL} \mathrm{~kg}^{-1} \mathrm{~min}^{-1}$. Glucose, as expected, significantly decreased with GLIB.

\section{Thermodilution-derived variables}

Transpulmonary thermodilution (PiCCO) revealed no significant differences in the estimated blood volumes
ITBV $\left(\sim 20 \mathrm{~mL} \mathrm{~kg}^{-1}\right)$ and GEDV $\left(\sim 16 \mathrm{~mL} \mathrm{~kg}^{-1}\right)$ or estimated EWLV $\left(\sim 9 \mathrm{~mL} \mathrm{~kg}^{-1}\right)$ between the four hypoxemia conditions (data not shown).

\section{Discussion}

For the present study we developed a model of moderate hypoxic hypoxemia, adapting reported canine hypoxia models $[40,41]$. Repetitive experiments were performed 


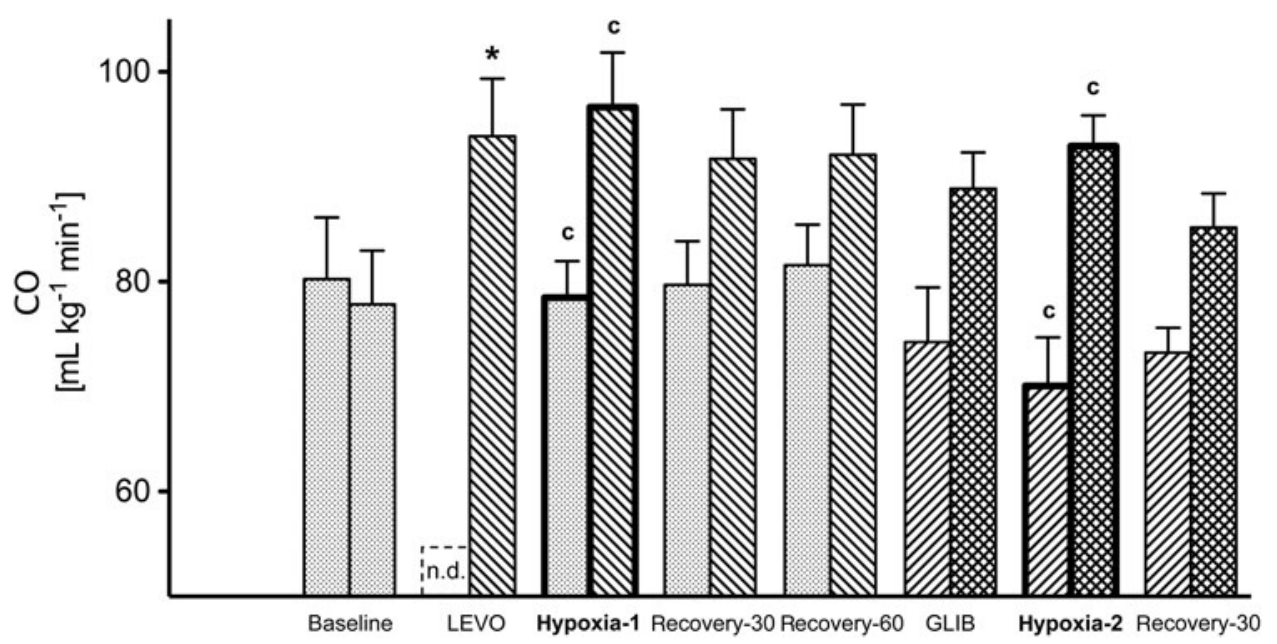

Fig. 2 Cardiac output. Cardiac output during normoxia $\left(\mathrm{FiO}_{2}\right.$ $\sim 0.3$, thin outlined bars) and the two hypoxia episodes $\left(\mathrm{FiO}_{2}\right.$ $\sim 0.1$, bold outlined bars) of the two experimental groups I (left bar per condition) and II (right bar per condition). Levosimendan was not given in group I, thus condition LEVO in group I is not determined (n.d.). Filling patterns: gray no pretreatment, downward stripes levosimendan (LEVO) pretreatment, upward stripes glibenclamide (GLIB) pretreatment, hatches levosimendan + glibenclamide pretreatment. Recovery-30 and recovery-60 are measurement points at 30 and $60 \mathrm{~min}$ of normoxic recovery. Mean \pm SEM for $n=6$ per group. ${ }^{a}$ No difference between hypoxia episodes, bsignificant difference within one group's hypoxia episodes, 'significant difference between the two groups' hypoxia episodes, *significant drug effects of LEVO and ${ }^{\$}$ GLIB

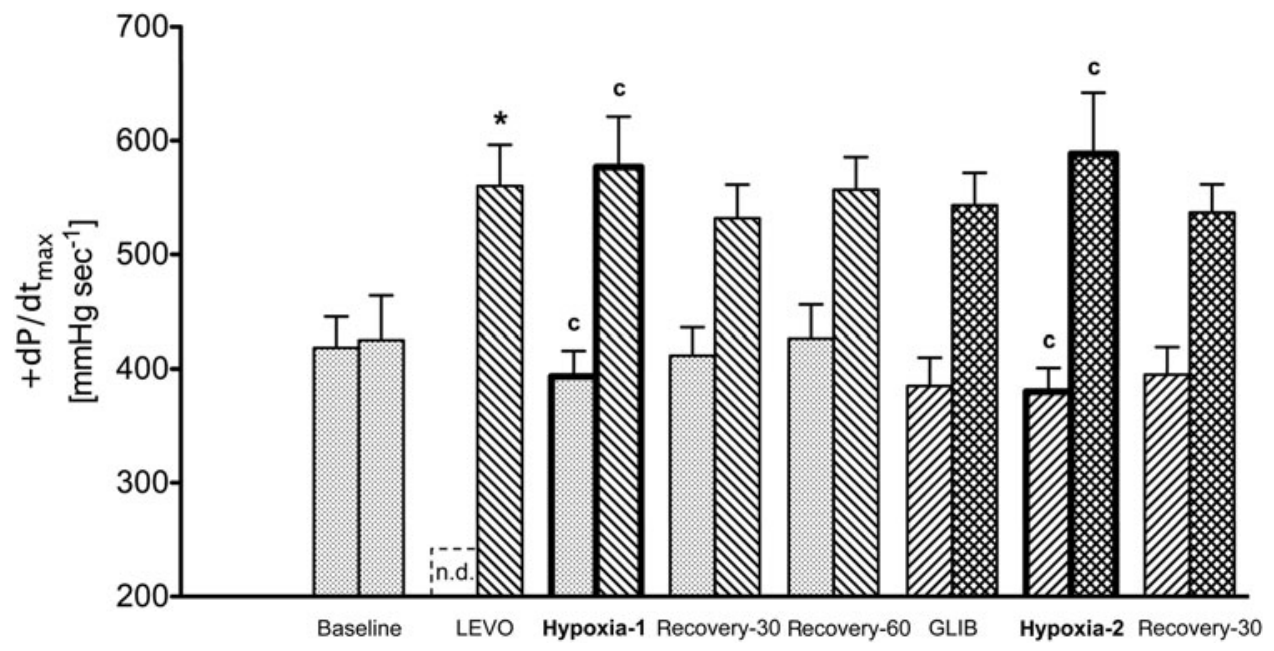

Fig. 3 Pressure-curve-derived contractility, $+\mathrm{d} P / \mathrm{d} t_{\max }$. Resulting $+\mathrm{d} P / \mathrm{d} t_{\max }$ during normoxia $\left(\mathrm{FiO}_{2} \sim 0.3\right.$, thin outlined bars $)$ and the two hypoxia episodes $\left(\mathrm{FiO}_{2} \sim 0.1\right.$, bold outlined bars $)$ of the two experimental groups I (left bar per condition) and II (right bar per condition). Levosimendan was not given in group I, thus condition LEVO in group $\mathrm{I}$ is not determined (n.d.). Filling patterns: gray no pretreatment, downward stripes levosimendan (LEVO) pretreatment, upward stripes glibenclamide (GLIB)

in a randomized mode on healthy, chronically instrumented dogs with intervals of $\geq 2$ weeks to exclude carryover effects and to minimize interindividual differences. Furthermore, the use of chronically instrumented animals avoided acute, surgical instrumentation and thus pretreatment, hatches levosimendan + glibenclamide pretreatment. Recovery-30 and recovery-60 are measurement points at 30 and 60 min of normoxic recovery. Mean \pm SEM for $n=6$ per group. ${ }^{a}$ No difference between hypoxia episodes, bsignificant difference within one group's hypoxia episodes, 'significant difference between the two groups' hypoxia episodes, *significant drug effects of LEVO and ${ }^{\$}$ GLIB confounders such as endocrine stress responses to surgery. In addition, our model allowed us to study the animals during sedation with sevoflurane and rocuronium alone, i.e., without need for analgesics or other confounding drugs [42]. 
In this study, two subsequent episodes of hypoxia were induced per group. While the first hypoxic episode served to elucidate the effect of LEVO pretreatment, the second hypoxic episode served to elucidate the role of $\mathrm{K}_{\mathrm{ATP}}^{+}$channels (by subsequently adding GLIB pretreatment, reported to block GLIB-sensitive $\mathrm{K}_{\mathrm{ATP}}^{+}$channels [26-30]). Between the two hypoxic episodes, an extended normoxic period was interposed to allow complete recovery of measured variables. In addition, to exclude the possibility that the first hypoxic episode was affecting the second with respect to measured variables, pilot experiments were performed, comparing a first with a second hypoxic period without adding any medication (i.e., no GLIB) in between. These pilot experiments demonstrated no differences between the first and second hypoxic episode, with respect to the measured variables.

Gastromucosal $\mu \mathrm{HbO}_{2}$ was continuously measured by reflectance spectrophotometry [43], with the light guide nontraumatically introduced via an orogastric tube $[9,39]$. Reflectance spectrophotometry allows determination of microcirculatory oxygen availability [44], and gastric endoluminal reflectance spectroscopy has been reported predominantly to measure capillary hemoglobin oxygenation of the mucosa [45].

Both hypoxia and the administered drugs may affect pulmonary endothelial permeability. Thus, we assessed EVLW by the PiCCO system, a method validated in anaesthetized dogs [37]. The EVLW data do not support pulmonary edema as cause of the small but significant differences in $\mathrm{PaO}_{2}$ between distinct hypoxia conditions (i.e., slightly lower with LEVO and/or GLIB), rendering an altered pulmonary shunt, as also reported for other vasoactive agents [46], as the most likely explanation.

LEVO appears to be a promising candidate agent to support the cardiocirculatory system during hypoxemia, particularly because circulatory stimulation by LEVO is reportedly independent of metabolic stimulation [9]. Our data support this concept, demonstrating that LEVO pretreatment resulted in improved systemic circulation (CO) also during hypoxemia without fueling aerobic $\left(\mathrm{VO}_{2}\right)$ metabolism. Thus, the pattern of increased $\mathrm{CO}$ at stable $\mathrm{VO}_{2}$ was present also during hypoxemia in LEVOpretreated subjects and, in turn, other factors triggered by hypoxemia, e.g., changed pharmacology [47], did not alter this pattern. Measured key modulators of vascular tone $\left(\mathrm{PaCO}_{2}, \mathrm{pH}\right.$, temperature, arterial $\left[\mathrm{K}^{+}\right]$and $\left.\left[\mathrm{Ca}^{2+}\right]\right)$ did not differ between the hypoxemic episodes, supporting that LEVO-specific mechanisms cause the differences in cardiovascular response.

The present study was designed to suggest a concept to improve the condition of the subject before an anticipated hypoxemia evolves; however, the majority of clinical hypoxemia episodes occur unexpectedly. Therefore, future studies will have to demonstrate if our findings are confirmed in the clinically more likely setting, i.e., with LEVO administered in a therapeutic rather than prophylactic approach [24, 48].

Increased CO during hypoxemia after LEVO pretreatment, compared to unpretreated hypoxemia, was associated with an increased $+\mathrm{d} P / \mathrm{d} t_{\max }$, compatible with positive inotropic effects of LEVO by myocardial $\mathrm{Ca}^{2+}$ sensitizing. LEVO, besides acting as a cardiac $\mathrm{Ca}^{2+}$ sensitizer, also activates $\mathrm{K}_{\mathrm{ATP}}^{+}$channels. Physiologically, various $\mathrm{K}_{\mathrm{ATP}}^{+}$channel isoforms exist, classified by their respective sulfonylurea receptors (SUR) in pancreatic $\beta$-cells (SUR-1), and striated (SUR-2A) and smooth muscle cells (SUR-2B). Vascular smooth muscle $\mathrm{K}_{\mathrm{ATP}}^{+}$channels link regional metabolism to perfusion, since intracellular ATP depletion (e.g., during hypoxia) triggers these channels, leading to hyperpolarization and thus vasorelaxation [8]. However, excessive activation of these $\mathrm{K}_{\mathrm{ATP}}^{+}$channels is involved in multiple pathological vasodilatory states, e.g., septic shock $[8,25]$. Thus, whether pharmacological activation of $\mathrm{K}_{\mathrm{ATP}}^{+}$channels under pathological conditions by LEVO is beneficial might also depend on the individual vasodilatory state. Pharmacologically, $\mathrm{K}_{\mathrm{ATP}}^{+}$channels are antagonized by sulfonylurea derivatives, with GLIB (glyburide) reported to unspecifically block all receptor isoforms, SUR-1, SUR-2A, and SUR-2B. GLIB has been reported to be effective as a $\mathrm{K}_{\mathrm{ATP}}^{+}$channel antagonist in dogs before, in similar dosages as applied in the present study [26-30]. Activity of GLIB in our model is suggested by the hypoglycemic response after GLIB pretreatment (SUR-1 effect), with arterial glucose decreased from baseline values of $\sim 100$ to $\sim 50 \mathrm{mg} \mathrm{dL}^{-1}$ (end of experiments). In addition, GLIB pretreatment significantly increased SVR, suggesting (partial) blockade of vascular $\mathrm{K}_{\mathrm{ATP}}^{+}$channels.

Thus, although GLIB pretreatment significantly increased SVR in this model, the demonstrated marked hypoglycemic effect of GLIB may limit its clinical use.

Combined GLIB + LEVO pretreatment resulted in significantly higher $\mathrm{CO}$ and $+\mathrm{d} P / \mathrm{d} t_{\max }$ than GLIB pretreatment alone during hypoxemia, compatible with the notion that mechanisms other than $\mathrm{K}_{\mathrm{ATP}}^{+}$channel opening contribute to LEVO effects, also during hypoxemia. Besides $\mathrm{Ca}^{2+}$ (re-)sensitization, LEVO's action as a phosphodiesterase (PDE) inhibitor could also contribute. In this regard, other PDE-III inhibitors have demonstrated positive systemic and regional gastrointestinal mucosal effects during hypoxemia [14].

Despite significant systemic differences, regional gastromucosal oxygenation did not differ between LEVOpretreated and unpretreated hypoxemia, which decreased equally to $\sim 30 \%$. Regional regulation of mucosal perfusion during hypoxemia could overrule the effects of LEVO, despite an increased $\mathrm{CO}$ and reduced SVR in LEVO-pretreated hypoxia. A possible mechanism is that local hypoxia activates vasodilatory $\mathrm{K}_{\mathrm{ATP}}^{+}$channels to such extents that LEVO can not confer significant additional vasodilation. Indeed after GLIB pretreatment, administered to block these vasodilatory $\mathrm{K}_{\mathrm{ATP}}^{+}$channels 
and thus to induce vasoconstriction, we observed clear trends towards lower $\mu \mathrm{HbO}_{2}$ both in LEVO-pretreated (from $32 \pm 4$ to $24 \pm 4 \%$ ) and unpretreated hypoxemia (from $30 \pm 4$ to $25 \pm 3 \%$ ). Interestingly, also in both groups arterial lactate concentrations were significantly lower after GLIB pretreatment. Since arterial $\mathrm{pH}$ and the other acid/base-related variables remained close to baseline under all hypoxemia conditions, we doubt that these significant differences in lactate concentration are caused by different perfusion states, rendering direct metabolic effects of GLIB more likely to contribute.

LEVO is clinically indicated for the treatment of chronic or acute cardiac failure, with promising results [15, 16], and indications have already extended to septic and toxic cardiac depression [17-23]. If our experimental data apply to the clinical setting, LEVO pretreatment may also be an option to support the cardiovascular system during hypoxemia, without fueling $\mathrm{VO}_{2}$, without aggravating systemic anaerobiosis markers, and without further compromising the regional gastromucosal oxygenation. Further studies will have to extend these experimental results to other hypoxia models and ultimately to the clinical setting.

Conflict of interest None of the authors is affiliated with any company involved. Funding came from departmental sources.

Open Access This article is distributed under the terms of the Creative Commons Attribution Noncommercial License which permits any noncommercial use, distribution, and reproduction in any medium, provided the original author(s) and source are credited.

\section{References}

1. Hilbert G, Gruson D, Vargas F, Valentino R, Favier JC, Portel L, Gbikpi-Benissan G, Cardinaud JP (2001) Bronchoscopy with bronchoalveolar lavage via the laryngeal mask airway in high-risk hypoxemic immunosuppressed patients. Crit Care Med 29:249-255

2. Jaber S, Amraoui J, Lefrant JY, Arich C, Cohendy R, Landreau L, Calvet Y, Capdevila X, Mahamat A, Eledjam JJ (2006) Clinical practice and risk factors for immediate complications of endotracheal intubation in the intensive care unit. Crit Care Med 34:2355-2361

3. Mort TC (2005) Preoxygenation in critically ill patients requiring emergency tracheal intubation. Crit Care Med 33:2672-2675

4. Sud S, Friedrich JO, Taccone P, Polli F, Adhikari NK, Latini R, Pesenti A, Guérin C, Mancebo J, Curley MA, Fernandez R, Chan MC, Beuret P, Voggenreiter G, Sud M, Tognoni G, Gattinoni L (2010) Prone ventilation reduces mortality in patients with acute respiratory failure and severe hypoxemia. Intensive Care Med 36:585-599

5. Zaobornyj T, Gonzales GF, Valdez LB (2007) Mitochondrial contribution to the molecular mechanism of heart acclimatization to chronic hypoxia. Front Biosci 12:1247-1259

6. Allen DG, Orchard CH (1987) Myocardial contractile function during ischemia and hypoxia. Circ Res 60:153-168

7. Day SM, Westfall MV, Fomicheva EV, Hoyer K, Yasuda S, La Cross NC, D'Alecy LG, Ingwall JS, Metzger JM (2006) Histidine button engineered into cardiac troponin I protects the ischemic and failing heart. Nat Med 12:181-189
8. Landry DW, Oliver JA (2001) The pathogenesis of vasodilatory shock. N Engl J Med 345:588-595

9. Schwarte LA, Picker O, Bornstein SR, Fournell A, Scheeren TW (2005) Levosimendan is superior to milrinone and dobutamine in selectively increasing microvascular gastric mucosal oxygenation in dogs. Crit Care Med 33:135-142

10. Mathie RT, Blumgart LH (1983) Effect of denervation on the hepatic haemodynamic response to hypercapnia and hypoxia in the dog. Pflugers Arch 397:152-157

11. Marshall JM, Metcalfe JD (1989) Analysis of factors that contribute to cardiovascular changes induced in the cat by graded levels of systemic hypoxia. J Physiol 412:429-448

12. Leach RM, Robertson TP, Twort $\mathrm{CH}$, Ward JP (1994) Hypoxic vasoconstriction in rat pulmonary and mesenteric arteries. Am J Physiol 266:223-231

13. Sandek A, Rauchhaus M, Anker SD, von Haehling S (2008) The emerging role of the gut in chronic heart failure. Curr Opin Clin Nutr Metab Care 11:632-639

14. Satoh T, Morisaki H, Ai K, Kosugi S, Yamamoto M, Serita R, Kotake Y, Takeda J (2003) Olprinone, a phosphodiesterase III inhibitor, reduces gut mucosal injury and portal endotoxin level during acute hypoxia in rabbits. Anesthesiology 98:1407-1414

15. Delaney A, Bradford C, McCaffrey J, Bagshaw SM, Lee R (2010) Levosimendan for the treatment of acute severe heart failure: a metaanalysis of randomised controlled trials. Int J Cardiol 138:281-289
16. Landoni G, Mizzi A, Biondi-Zoccai G, Bignami E, Prati P, Ajello V, Marino G, Guarracino F, Zangrillo A (2010) Levosimendan reduces mortality in critically ill patients. A meta-analysis of randomized controlled studies. Minerva Anestesiol 76:276-286

17. Parissis JT, Rafouli-Stergiou P, Stasinos V, Psarogiannakopoulos P, Mebazaa A (2010) Inotropes in cardiac patients: update 2011. Curr Opin Crit Care 16:432-441

18. Leppikangas H, Ruokonen E, Rutanen J, Kiviniemi V, Lindgren L, Kurola J (2009) Levosimendan as a rescue drug in experimental propranolol-induced myocardial depression: a randomized study. Ann Emerg Med 54:811-817

19. Creteur J, Bouckaert Y, Melot C, Vincent JL (2006) Effects of levosimendan on systemic and regional hemodynamics in septic myocardial depression. Intensive Care Med 32:790

20. DeBacker D, Taccone FS, Radermacher P (2007) Levosimendan in septic shock: another piece in the puzzle, but many pieces are still lacking. Intensive Care Med 33:403-405

21. Dubin A, Murias G, Sottile JP, Pozo MO, Barán M, Edul VS, Canales HS, Etcheverry G, Maskin B, Estenssoro E (2007) Effects of levosimendan and dobutamine in experimental acute endotoxemia: a preliminary controlled study. Intensive Care Med 33:485-494

22. Morelli A, De Castro S, Teboul JL, Singer M, Rocco M, Conti G, De Luca L, Di Angelantonio E, Orecchioni A, Pandian NG, Pietropaoli P (2005) Effects of levosimendan on systemic and regional hemodynamics in septic myocardial depression. Intensive Care Med 31:638-644 
23. Scheiermann P, Ahluwalia D, Hoegl S, 32. Maybauer DM, Salsbury JR, Westphal Dolfen A, Revermann M, Zwissler B, Muhl H, Boost KA, Hofstetter C (2009) Effects of intravenous and inhaled levosimendan in severe rodent sepsis. Intensive Care Med 35:1412-1419

24. Morelli A, Ertmer C, Pietropaoli P, Westphal M (2009) Reducing the risk of major elective non-cardiac surgery: is there a role for levosimendan in the preoperative optimization of cardiac function? Curr Drug Targets 10:863-871

25. Landry DW, Oliver JA (1992) The ATP-sensitive $\mathrm{K}^{+}$channel mediates hypotension in endotoxemia and hypoxic lactic acidosis in dog. J Clin Invest 89:2071-2074

26. Fukunari A, Miyai H, Shinagawa K, Kawahara K, Nakajima T (1997) Y-26763 protects the canine heart from a stunning injury through opening of the KATP channels. Eur J Pharmacol 323:197-204

27. Ito M, Pride HP, Zipes DP (1994) Glibenclamide enhances but pinacidil reduces attenuation in sympathetic responsiveness after acute coronary artery occlusion. Circ Res 75:379-392

28. Kersten JR, Montgomery MW, Pagel PS, Warltier DC (2000) Levosimendan, a new positive inotropic drug, decreases myocardial infarct size via activation of K(ATP) channels. Anesth Analg 90:5-11

29. Yao Z, Gross GJ (1993) Glibenclamide antagonizes adenosine A1 receptormediated cardioprotection in stunned canine myocardium. Circulation 88:235-244

30. Yao Z, Gross GJ (1994) A comparison of adenosine-induced cardioprotection and ischemic preconditioning in dogs. Efficacy, time course, and role of KATP channels. Circulation 89:1229-1236

31. Lange M, Morelli A, Westphal M (2008) Inhibition of potassium channels in critical illness. Curr Opin

Anaesthesiol 21:105-110
M, Maybauer MO, Salzman AL, Szabó C, Westphal-Varghese BB, Traber LD, Traber DL (2004) The ATP-sensitive potassium-channel inhibitor glibenclamide improves outcome in an ovine model of hemorrhagic shock. Shock 22:387-391

33. Musser JB, Bentley TB, Griffith S, Sharma P, Karaian JE, Mongan PD (2004) Hemorrhagic shock in swine: nitric oxide and potassium sensitive adenosine triphosphate channel activation. Anesthesiology 101:399-408

34. Schwarte LA, Picker O, Bornstein SR, Fournell A, Scheeren TW (2005) Levosimendan is superior to milrinone and dobutamine in selectively increasing microvascular gastric mucosal oxygenation in dogs. Crit Care Med 33:135-142 Bettschart-Wolfensberger R (2005) Closed system anaesthesia in dogs using liquid sevoflurane injection; evaluation of the square-root-of-time model and the influence of $\mathrm{CO}_{2}$ absorbent. Vet Anaesth Analg 32:168-177

36. Blumenthal SR, Skoula CM, Gordon BE (1998) Relationship between inspiratory pressure and tidal volume in the anesthetized canine. Lab Anim Sci 48:69-73

37. Katzenelson R, Perel A, Berkenstadt H, Preisman S, Kogan S, Sternik L, Segal E (2004) Accuracy of transpulmonary thermodilution versus gravimetric measurement of extravascular lung water. Crit Care Med 32:1550-1554

38. Kim HK, Pinsky MR (2008) Effect of tidal volume, sampling duration, and cardiac contractility on pulse pressure and stroke volume variation during positive-pressure ventilation. Crit Care Med 36:2858-2862
35. Boller M, Moens Y, Kästner SB,
39. Schwartges I, Schwarte LA, Fournell A, Scheeren TW, Picker O (2008) Hypercapnia induces a concentrationdependent increase in gastric mucosal oxygenation in dogs. Intensive Care Med 34:1898-1906

40. Kohzuki H, Sakata S, Misawa H, Takaki $\mathrm{M}$ (2002) $\mathrm{O}_{2}$ delivery and the venous $\mathrm{PO}_{2}-\mathrm{O}_{2}$ uptake relationship in pump-perfused canine muscle. Exp Physiol 87:53-61

41. Kato R, Sato J, Nishino T (1998) Milrinone decreases both pulmonary arterial and venous resistances in the hypoxic dog. Br J Anaesth 81:920-924

42. Ebert TJ, Ficke DJ, Arain SR, Holtz MN, Shankar H (2005) Vasodilation from sufentanil in humans. Anesth Analg 101:1677-1680

43. Knotzer H, Maier S, Dünser MW, Hasibeder WR, Hausdorfer H, Brandner $\mathrm{J}$, Torgersen C, Ulmer H, Friesenecker B, Iannetti C, Pajk W (2006) Arginine vasopressin does not alter mucosal tissue oxygen tension and oxygen supply in an acute endotoxemic pig model. Intensive Care Med 32:170-174

44. Jakob SM, Takala J (2002) ARDS. Monitoring tissue perfusion. Crit Care Clin 18:143-163

45. Severinghaus JW (2003) Continuous positive airway pressure, shock therapy, and gastric mucosal oxygenation. Crit Care Med 31:1870-1871

46. Adnot S, Radermacher P, Andrivet P, Dubois-Rande JL, Dupeyrat A, Lemaire F (1991) Effects of sodiumnitroprusside and urapidil on gas exchange and ventilation-perfusion relationships in patients with congestive heart failure. Eur Respir J 4:69-75

47. Mace SE (1990) Effect of hypoxemia on pharmacokinetics of endotracheal lidocaine in dogs. Resuscitation 20:41-48

48. Brezina A, Riha H, Pirk J (2009) Prophylactic application of levosimendan in cardiac surgical patients with severe left ventricle dysfunction. Exp Clin Cardiol 14:31-34 